\title{
Association between Social-Cognitive Factors and Sexual Intention towards Pre-Marital Sex Activity among School-Going Late Adolescents in Kuantan, Pahang
}

Fa'iza Abdullah¹, Nur Akmanidar Zainuddin¹, Samsul Draman¹, Nor Azlina A.Rahman²

${ }^{1}$ Department of Family Medicine International Islamic University Malaysia, ${ }^{2}$ Kulliyyah of Allied Health Sciences

Introduction: The Theory of Planned Behavior (TPB) is determined by four main domains of social-cognitive factors; attitudes, social-norms, self-efficacy and sexual intention. This study aim to identify the socio-demographic and socio-cognitive factors associated with sexual intention towards premarital sex among school-going late adolescent. Materials and method: Cross-sectional study was conducted in nine government secondary schools in Kuantan district between January-July 2018. A total of 466 self-administered validated Youth Sexual Intention Questionnaires(YSIQ) data are collected among unmarried students aged 18-19-year-old. Statistical analyses were done using IBM SPSS version 22.0. Results: Out of 466 participants, $67.4 \%, 68.2 \%, 64.4 \%$ are Malays, Females and Muslims. Simple logistic regression showed for every one unit increase in permissive attitude, social-norms and selfefficacy scores, there were 1.424, 1.303 and 1.215 times increase risk of having sexual intention, with $\mathrm{p}$-value of 0.001 each and $95 \% \mathrm{Cl}$ of odds ratio(OR) 1.268$1.600,1.191-1.425$ and 1.066-1.386 respectively. Multivariate logistic regression showed that female had lower risk of having sexual intention( $p=0.001,0 R=0.163$, $\mathrm{Cl}=0.058-0.462)$. Non-Malays and ever-smoker students had higher risk compared to Malay and non-smoker towards having sexual intention with $p=0.001$ $(\mathrm{OR}=5.110, \mathrm{Cl}=1.881-13.886)$ and $\mathrm{p}=0.019(\mathrm{OR}=3.288, \mathrm{Cl}=1.218-8.875)$ respectively. For every unit increase in permissive attitude score, there was 1.236 times increase risk of having sexual intention with $\mathrm{p}=0.002(95 \% \mathrm{Cl}, \mathrm{OR}=1.084-1.410)$. Conclusion: The study showed the risk of having sexual intention was higher among males, nonMalay, ever-smoker students; and those with higher permissive attitude scores. Peer education intervention programs are necessity for school-going students to improve the permissive attitude in averting risk behavior that may lead to sexual intention towards pre-marital sex activity. The study should be expanded to adolescent who are no longer in school or in suburban areas. 